\title{
Review \\ Injuries and Pain Associated with Goalkeeping in Football-Review of the Literature
}

\author{
Jarosław Muracki 1,*(D), Sebastian Klich ${ }^{2}$ (D), Adam Kawczyński ${ }^{2}$ (D) and Shellie Ann Boudreau ${ }^{3}$ (D) \\ 1 Faculty of Health and Physical Education, Institute of Physical Culture Sciences, University of Szczecin, \\ 70-453 Szczecin, Poland \\ 2 Department of Paralympic Sport, University School of Physical Education in Wroclaw, \\ 51-612 Wroclaw, Poland; sebastian.klich@awf.wroc.pl (S.K.); kawczynski.a@gmail.com (A.K.) \\ 3 SMI, Department of Health Science and Technology, Aalborg University, 9220 Aalborg, Denmark; \\ sboudreau@hst.aau.dk \\ * Correspondence: jaroslaw.muracki@usz.edu.pl
}

check for updates

Citation: Muracki, J.; Klich, S.; Kawczyński, A.; Boudreau, S.A Injuries and Pain Associated with Goalkeeping in Football-Review of the Literature. Appl. Sci. 2021, 11 , 4669. https://doi.org/10.3390/ app11104669

Academic Editor: Mark King

Received: 13 April 2021

Accepted: 17 May 2021

Published: 19 May 2021

Publisher's Note: MDPI stays neutral with regard to jurisdictional claims in published maps and institutional affiliations.

Copyright: (c) 2021 by the authors. Licensee MDPI, Basel, Switzerland. This article is an open access article distributed under the terms and conditions of the Creative Commons Attribution (CC BY) license (https:// creativecommons.org/licenses/by/ $4.0 /)$.
Featured Application: Physiotherapy in football, designing programs for injury prevention, goalkeeping coaching.

\begin{abstract}
Knowledge and research about football goalkeeper (GK) injuries are scarce, which prevents the development of evidence-based injury prevention programs. Fortunately, progress is evident in injury prevention strategies in outfield football players. However, a GK fulfills a unique role, and an injured GK can substantially impact a team. Thus, there is a need to clarify and summarize current knowledge concerning football goalkeeper pain and injuries. This narrative review aims to present the best-evidence synthesis of knowledge about football GK injuries and pain, their type, location, and incidence. A secondary aim is to contrast these findings with outfield players and identify knowledge gaps. Scientific databases were searched for the following indexed terms: goalkeeper, injury, soccer, and football. Original papers, including case studies and systematic reviews published from August 1994 to March 2021, were screened for relevance using a priori criteria and reviewed. Commonly described injuries are fractures, luxation and dislocations in the fingers, hand and wrist. The quadriceps femoris and forearms muscles are the most frequently described muscle and tendon injuries. Further, football GK injuries differ in type, location, and incidence compared to outfield players. Whether GKs suffer fewer injuries than players in other positions, whether GK suffer more injuries in training than matches, and whether they sustain more upper limb injuries comparing to field players is still unclear and controversial. Few studies assess pain, and current data point to the development of hip and groin, thigh, knee, arm and forearm pain resulting from training and match play. Due to the crucial role of GK in the football team, it is recommended to use the injury burden as a parameter considering the number and time-loss of injuries in future studies.
\end{abstract}

Keywords: goalkeeper; injury; pain; soreness; football; soccer; muscle; tendon; fracture; luxation

\section{Introduction}

Football is a popular sport with the highest risks for injury [1,2] and has the most significant number of injured players yearly. However, injury and pain assessments in football goalkeepers (GKs) are scarce relative to their essential role. Indeed, a football GK is vital, and the game mechanics differ entirely from outfield positions. Undoubtedly, GKs' playing and training conditions can put them at a high risk of injury as well. Thus, a comprehensive understanding of sustained injuries and pain reports in football GKs would be valuable for medics, physiotherapists and coaches.

Since the 1990s, the GK's position has evolved dynamically. Although shot stopping will always be an essential skill, newer demands imposed on modern GKs, such as asecuration of the defensive line, making clearances and active foot play, bring additional 
injury risks. GKs fulfill unique and crucial defensive and offensive roles. As a result, GKs often possess different abilities and attributes than outfield players. For example, GKs demonstrate better high jump performance but perform worse on speed and $\mathrm{VO} 2$ max tests than outfield players. Thus, it would be reasonable to expect that the rate and type of injuries may also differ.

Such differences are in part due to the selection process. In professional football, criteria for GKs and field players are different and include biological age, maturity, body height, predicted height, handgrip strength and jump performance [3]. This may explain why GKs tend to be statistically higher, heavier and have more \% of body fat than any other player or age group [4].

Nowadays, most publications concerning sustained injury and pain in GKs consist of case studies, a small sample size, or provide data using different methodology and definitions which impede direct comparison. Thus, insufficient and varied studies preempt a systematic review.

\subsection{Characteristics of Football Goalkeepers Play and Risk of Injury}

\subsubsection{Offensive Scenarios}

Depending on the game, GKs' actions are between $60-80 \%$ offensive play [5-9]. A modern-day GK often uses their feet to play the ball to gain an advantage for his team or initiate counterattacks. GKs often make passes at the distances of $50 \mathrm{~m}$ or more in contrast to outfield players who more often pass at shorter distances [8]. GKs initiate offensive play by goal kicking, which is played only with the feet due to the rules. Offensive in action play constitutes $60 \%$ throwing and $40 \%$ passing with the feet in training game conditions [10]. Furthermore, effective GKs combine various abilities and characteristics, including explosive force, speed, and coordination with their high body height $[3,4,7,8]$.

\subsubsection{Defensive Scenarios}

An essential skill of a GK's defensive gameplay is shot stopping. On average, GKs of the highest level perform about 23 different defensive actions per match [5]. For these games, there is a varying frequency of cross interceptions, one-to-one duels, and clearouts $[5,7,11]$. There is approximately $6.2 \pm 2.7$ dives, $3.8 \pm 2.3$ jumps and $18.7 \pm 6$ very dynamic displacements (forward, sideways, and backward) per game [5]. Results from other studies confirm these findings (on average: $10 \pm 1$ dives, $15 \pm 5$ jumps, $8 \pm 3$ high speed changes of direction and $16 \pm 3$ explosive efforts) and add similar data characterizing goalkeeping training (on average $51 \pm 11$ dives, $43 \pm 15,34 \pm 12$ high speed changes of direction and $70 \pm 18$ explosive efforts) [12].

\subsubsection{Distance Covered during a Match}

GKs cover far shorter distance during gameplay than outfield players $[8,10]$. During 90 min gameplay, on average, elite outfield players cover a distance of 10 to $12 \mathrm{~km}$ [13-20]. This distance includes sprinting (approximately every $90 \mathrm{~s}$ ), walking and long-distance running (about $60 \mathrm{~m}$ ) [21]. In contrast, GKs cover shorter distances, ranging from 3.5 to $6.5 \mathrm{~km}$ during a match, with an average of $5.5 \mathrm{~km}$. The majority of this distance is walking [7].

\subsubsection{Risky Conditions and Situations}

According to many authors [22-25] GKs get into a number of situations during training and matches which pose a high risk of injury. For GKs there are additional specific situations which can cause injury risks that are not present in the actions of field players. Such actions are crosses interceptions, $1 \mathrm{v} 1$ duels and shot stopping with diving techniques.

Non-contact injuries are caused by dynamic movements, including quick changes of direction, sprints, dives, jumps, throws, and kicks. Jumps and shot stopping, as well as diving saves, require large and rapid generation of forces at push-off [11,26-28] and include many diving techniques, which mostly end in hitting the ground [12]. Therefore, 
it is reasonable to anticipate that shot stopping training can lead to contusions, bruises, abrasions, wounds and even fractures [29]. Moreover, repetitive impact of diving saves may result in elbow and other upper extremity injuries. Additionally, some diving saves require the body to contort into extreme ranges of motion. The goal of deflecting the ball may cause muscle strain, tendon rupture, or joint sprains [25]. Shot stopping by catching is considered ideal as the opponent's attack ends and a possibility of rebound or second shot is reduced. However, catching powerful shots or deflecting the ball is not without risk. Such catches can cause sprains, dislocations and fractures of wrists, hands or fingers [30-32]. During throwing, an excessive range of motion combined with a high level of dynamics can lead to injuries, especially in the dominant arm [33,34].

Contact (with an opponent or a teammate) injuries are caused by colliding with other players, being hit by the ball, falling on the ground and, in exceptional cases, even hitting a goal post. Passing under pressure or sweeping before a rival reaches the ball puts GKs at the risk of being kicked, hit or rammed by the opponent. Such situations can lead to bruises, abrasions, wounds, muscle strains, joint sprains and fractures. Similarly, aerial play and cross interceptions involve a high risk of colliding with another player [35]. At the same time, landing from aerial play can lead to joint sprains, muscle and tendon strains or ruptures. Additionally, $1 \times 1$ defensive situations often start dynamically and end in diving under opponents' feet, blocking the ball, or reaction saves.

A risk of trauma in the lower limbs is connected with running, kicking the ball, jumping, accelerating, decelerating, and changing directions both in GKs and in field players. In addition, kicking a ball and contact with other players challenging for a ball or making a tackle can result in trauma. Long passes demand dynamic movement with a lot of force production, leading to muscle and tendon strains, muscle attachments, avulsions (avulsion fractures) [36,37], or sprains-especially ankle sprains [2].

The factors described above, i.e., quick movements, excessive range of motion and impacts are apparent sources of pain and may cause injuries.

\subsection{Pain and Injury Definitions}

Due to the fact that the topic of football GK injuries rarely shows up in the scientific literature and that analyzed papers arose over a long period of time, the studies differ in injury and pain definitions, as well as in methods of quantifying the occurrence of an injury. There are different parameters used-i.e., injury incidence, injury risk or the injury hazard ratio. The differences cause difficulties in comparison and interpretation of the results. It is recommended to use definitions of injury and methods described in the "Consensus statement on injury definitions and data collection procedures in studies of football (soccer) injuries" by Fuller et al. [38]. This document defines injury as any physical complaint sustained by a player that results from a football match or football training, irrespective of the need for medical attention or time-loss from football activities. An injury resulting in medical attention is considered a "medical-attention" injury, and an injury resulting in a player being unable to fully participate in subsequent football training or match play a "time-loss" injury. This definition also includes absence due to illness, disease and mental complaints.

Bahr (2009) claims that, depending on an injury definition, the injury incidence can be very low (time-loss or medical attention definitions), despite high prevalence of pain from pain indicating surveys [39]. A widely used time-loss injury definition overlooks scenarios where an injury may lead to a time-loss injury in one athlete but not in another, which makes pain monitoring even more significant.

The International Association for the Study of Pain (IASP) defines pain as "An unpleasant sensory and emotional experience associated with or resembling that associated with, actual or potential tissue damage" [40]. However, Kumar and Elavarasi suggest that pain should be considered as "the subjective interpretation of the discomfort" [41], which emphasizes the subjectiveness of the phenomenon. 


\section{Aim}

This narrative review aimed to provide a best-evidence synthesis about football GK injuries and pain, in particular, their type, location, incidence, and risks which may occur during game and training conditions. A secondary aim was to contrast these findings, where appropriate, with outfield players and identify knowledge gaps.

\section{Materials and Methods}

Pubmed, Web of Science and Google Scholar databases were searched for indexed terms, including the following key words: goalkeeper, injury, soccer, and football. Other sources of data were references of analyzed papers. Only English-written studies on football/soccer goalkeepers, citing injury type, location, incidence, and or risk, were screened for inclusion. Over two hundred original papers, including case studies published from August 1994 to March 2021, were screened for relevance using a priori criteria. Due to the fact that the focus of this article is on injuries and pain, articles on treatment, postsurgery complications, post surgery pain, and rehabilitation were excluded. The methods aimed to provide best-evidence synthesis useful especially for researchers working on preventive programs or particular injuries, medicians, physioterapeuts and coaches.

After excluding articles that did not match the criteria in the search and selection process, the authors included 25 case studies in the review. A summary (Table 1) of 10 articles that compare incidence of injuries in different positions in football, including goalkeepers, was prepared and another table comparing injury location in GK of 6 studies was provided. To describe the presented topic the authors analyzed and quoted aditional 51 other original papers, including systematic reviews. Overall, 92 articles have been quoted in this narrative review.

\section{Discussion}

\subsection{Outfield Players' Injuries vs. Goalkeepers' Injuries}

On average, an elite football player suffers from 1.5 to 7.6 injuries per 1000 training hours and 12 to 35 injuries per $1000 \mathrm{~h}$ of a match [23]. Kirkendall and Dvorak reported that the most common injury location in all positions was the lower limb $(67.7 \%)$, followed by the upper limb (13.4\%) [42].

Table 1. Injuries in GKs and field players.

\begin{tabular}{ccc}
\hline Study & Match/Training & Main Findings \\
\hline Andersen et al. (2003) [43] & Match & Less injuries in GK \\
\hline Aoki et al. (2012) [44] & Match & Less injuries in GK \\
\hline Arliani et al. (2011) [45] & Match & Less injuries in GK \\
\hline Kristenson et al. (2013) [46] & Match and training & Less injuries in GK \\
\hline Deehan et al. (2007) [47] & Match and training & Less injuries in GK \\
\hline Carling et al. (2009) [48] & Match & Less injuries in GK \\
\hline Martín-San Agustín et al. & Match and training & $\begin{array}{c}\text { Less injuries comparing to FW } \\
\text { and MDF, more injuries } \\
\text { comparing to DF }\end{array}$ \\
\hline $\begin{array}{c}\text { Dauty\&Collon (2011) [50] } \\
\text { (2001) [51] }\end{array}$ & Match and training & $\begin{array}{c}\text { No differecne according to } \\
\text { player position }\end{array}$ \\
\hline $\begin{array}{c}\text { Morgan and Oberlander } \\
\text { Timpka et al. (2008) [52] }\end{array}$ & Match and training & $\begin{array}{c}\text { No differecne according to } \\
\text { player position }\end{array}$ \\
\hline GK- & Match & $\begin{array}{c}\text { No differecne according to } \\
\text { player position }\end{array}$ \\
\hline
\end{tabular}

GK-goalkeepers, FW—-forwards, MDF-midfielders, DF-defenders. 
Many studies show that GKs suffer fewer injuries than field players. There are also studies indicating that GKs do not differ in injury incidence from field players (Table 1).

GKs suffer more injuries during training than matches due to much more explosive actions and goalkeeper-to-player interactions comparing to matches $[9,12,25]$. This stands in contrast to field players who suffer more injuries during matches than training [2,46] and is typical for many other sports [2]. However, different studies present contrasting results, i.e., in the study of Kristenson, GKs' injury incidence was higher in competition than in training (12.1 vs. 3.5, respectively) [46], which is proven also in female football GKs by the study of Martín-San Agustín et al. with the results of IR 14.04 in matches vs. 2.57 in training [49]. Strand et al. published a study of Norwegian elite GKs showing that GK injury incidence was 27.9 per 1000 playing hours of matches, 23.6 for specific GK training and 9.1 for other types of exercise [35].

GKs cover shorter distance during play and training [7,9] and use the upper limbs more frequently to execute deffenisve and offensive actions comparing to field players. When it comes to the distribution of injuries location, there are controversies in the literature. Some authors claim that GKs have higher upper limbs than lower limbs injuries incidence [23,46,53], especialy of fingers, hands and wrists [53] but results of other studies do not agree with this statement. (Table 2). In the study of Strand et al. injuries of the upper limbs represented 36\% of all injuries in GKs [35]. Hart et al. and Ekstrand et al. reported a greater risk of shoulder injuries in GKs than in outfield players [54,55]. The most injured area of the shoulder is the rotator cuff, causing partial or total tear.

Table 2. Injuries location-results by different studies.

\begin{tabular}{|c|c|c|c|c|c|c|}
\hline Study & Par. & Total & $\begin{array}{l}\text { Head, } \\
\text { Neck }\end{array}$ & Trunk & Upper Limbs & $\begin{array}{l}\text { Lower } \\
\text { Limbs }\end{array}$ \\
\hline $\begin{array}{c}\text { Aoki et al. (2012) } \\
\text { [44] }\end{array}$ & IRR & - & 4.06 & 1.30 & 1.63 & 5.93 \\
\hline $\begin{array}{l}\text { Kristenson et al. } \\
\quad \text { (2013) [46] }\end{array}$ & II & 4.6 & 0.2 & 0.7 & 1.0 & 2.7 \\
\hline $\begin{array}{l}\text { Ekstrand et al. } \\
\text { (2013) [55] }\end{array}$ & II & & & & 0.8 & \\
\hline $\begin{array}{l}\text { Goodman et al. } \\
\text { (2018) [25] }\end{array}$ & II & & & & $\begin{array}{l}0.83 \text { (shoulder } \\
\text { and elbow) }\end{array}$ & \\
\hline $\begin{array}{l}\text { Hwang-Bo and } \\
\text { Joo (2019) [56] }\end{array}$ & $\%$ & & & $\begin{array}{l}12 \% \text { (head } \\
\text { and trunk) }\end{array}$ & $31 \%$ & $57 \%$ \\
\hline $\begin{array}{c}\text { Błażkiewicz et al. } \\
\text { (2018) [57] }\end{array}$ & $\%$ & & & $\begin{array}{l}9.6 \% \text { (head } \\
\text { and trunk) }\end{array}$ & $34.6 \%$ & $55.8 \%$ \\
\hline
\end{tabular}

IRR—Injury Risk Ratio. II—Injury Incidence.

A report by Kristenson et al. about injuries in all football players positions with an emphasis on newcomers to professional football showed higher injury hazard rates (HR) for field players (defenders $=1.91$, midfielders $=1.78$, forwards $=1.82$ ) compared to GKs $(H R=1.0)$ as defined by time-loss injuries. Most injuries occurred with no contact $(\mathrm{HR}=3.2)$ compared to those resulting from contact $(\mathrm{HR}=0.9)$ with another player or with an object $(\mathrm{HR}=0.3)$. Most $\mathrm{GK}$ injuries concerned muscle and tendon (injury incidence$\mathrm{II}=1.8)$ followed by joint/ligament $(\mathrm{II}=1.2)$. The most common locations were the lower limbs (II = 2.7) compared to the upper limbs, trunk and head/neck (1.0; 0.7; 0.2 respectively). GKs had higher II of the upper limbs and trunk and higher II caused by contact with an object (ball, goalpost) compared to field players. Overall, (all playing positions), injury HR increased with age and peaked for experienced players 29-30 years old. The experienced players had significantly higher injury incidence (II) than newcomers for muscle and tendon injuries (3.6 vs. 1.6 respectively) and for the lower limbs (6.8 vs. 4.4 respectively). Generally, newcomers (to a high level football) had lower injury hazard rates (HR) than 
established players ( 0.77 vs. 1.0 respectively), but they had a higher risk of fractures. In the discussion section the authors underlined the need of creating different prevention strategies for GKs [46].

\subsection{Pain in Outfield Players}

The most frequent location of pain complaints in outfield players is the hip and groin region, which comprises approximately $70 \%$ of football players during the full-time season $[58,59]$. The authors cited above observed recurring pain in the hip and groin region and a significant correlation with decreased function and quality of life. Furthermore, groin pain represents a serious problem due to high frequency of long-term symptoms and a high risk of pain recurrence [59]. Hölmich et al. reported a high impact of adductor muscle and iliopsoas muscle pain on future injuries in the hip joint and groin area [60].

\subsection{Pain in Goalkeepers}

The author's own research shows that during a training camp football GKs suffer different types of pain (muscle pain, joint pain, pain caused by impact), in which muscle pain is the most frequent and covers the biggest body area (Table 3) Every GK examined in the study indicated impact caused pain $(100 \%, \mathrm{n}=24), 96 \%$ (23 of 24$)$ stated muscle pain and $67 \%$ (16 of 24) indicated joint pain not caused by impact [61].

Table 3. Different types of pain in football goalkeepers $(n=24)$ following training during preseason training camp (based on Muracki et al., 2019 [61]).

\begin{tabular}{cccc}
\hline Type of Pain & Most Frequent Localization & $\boldsymbol{n}$ out of $\mathbf{2 4}$ & $\mathbf{\%}$ of all \\
\hline \multirow{2}{*}{ Impact caused pain } & Hip and groin & 16 & $67 \%$ \\
Muscle pain & Forearm and arm & 16 & $67 \%$ \\
Joint pain & Thighs & 21 & $88 \%$ \\
& Hip and groin & 7 & $29 \%$ \\
\hline
\end{tabular}

Typically, a professional GK participates in football activity 5 to 10 times a week (including team trainings, goalkeeping sessions and all other types of football training) and plays 1-2 matches weekly during the starting season [12]. Under these conditions, pain can be always present. Pain can vary in type and localization, but if it gains a status of the same type in the same localization, it may by an alarm signal for a player and medical staff. Pain often accompanies recurring micro-traumas [44] making regular pain monitoring necessary for injury prevention.

\subsection{Goalkeepers' Injuries of Upper Limbs}

The analysis of the literature points to the conclusion that treatment of the upper limb injuries in GKs is generally successful. Conservative treatment is mainly used, the time-loss period is short (2-12 weeks) and coming back to the same sport level is very likely. Timeloss, however, is typically greater in GKs compared with players in other positions [53]. Of all upper limbs injuries only shoulder traumas are more severe and lead to even longer time-loss injuries, which makes the shoulder injury burden more significant $[23,54]$.

\subsubsection{Fingers, Hand and Wrist}

Frequent hand contact with the ball is the reason why football GK is prone to injuries of hands [62]. GKs had a 7-fold higher incidence of the forearm, hand and wrist injuries and an over 1-week longer mean layoff time compared with outfield players. Most of these injuries were fractures [53]. The results presented by Muracki et al. showed that during a training camp $21 \%$ of GKs ( 5 of 24 ) indicated pain caused by impact in fingers, hand and wrist and 17\% of GKs (4 of 24) indicated joint pain in these areas [61] (Table 3). The main cause of finger injuries is contact with the ball during unfortunate catching. This leads to fractures, tendon ruptures, mallet fingers and finger sprains. The hand, wrist and forearm and their joints are functional elements which are endangered by frequent 
contact with strong shots which lead to overextension mechanism. These types of repeated microtrauma may cause unidentified pain or stress fractures in the wrist bones. The impact of the ball against the hands while trying to catch or deflect produces a similar mechanism of axial loading and forced extension of the wrist to the one which occurs during a fall when a person tries to support himself with the hand. The size and weight of the ball as well as force used to shoot play a crucial role in the injury hazard ratio in children football. According to Boyd, Brownson and Hunter the hazard ratio is increased when adult size ball is used, an adult shoots and is highly increased when there is a combination of these conditions. The main finding of their study was that $80 \%$ of fractures in children aged 11 or under were caused by impact of adult size ball. In children aged 12-15, only one fracture resulted from a junior size ball and $21 \%$ of the fractures were caused by an adult kicking the ball. Goalkeeper gloves were used in $41 \%$ cases. The authors recommend using the appropriate ball size to the age of practicing GKs and players and having increased awareness of this particular injury risk [29].

Another typical hazardous situation is punching-when a GK tries to hit a ball the wrist should be straightened. Even slight extension or flexion can lead to exceeding the range of motion, which may result in sprain or fracture of the wrist or forearm bones. Yamamoto et al. (2019) underline that trapezoid fractures can be easily overlooked during an initial hospital visit. The authors claim that if there is pain in the wrist and hand after punching a ball the presence the wrist fracture should be examined [31]. The symptoms can be discrete or ambiguous, which makes diagnosis difficult. If diagnosis and treatment is implemented quickly, a prognosis is good. However, due to poor blood supply to the wrist bones, old fractures can make conservative treatment difficult and surgical treatment may be necessary.

Long term consequences of GK playing and training for the wrist, hand, and fingers were analyzed by Hilber et al. Their study shows that, after 20 years of playing recreational football, GKs had more restricted finger movements, experienced more pain and swelling, as well as higher levels of instability in the wrist and finger joints comparing to outfield players [32].

The extraordinary injury mechanism occurring in GKs is connected with the construction of football goals. The hooks used to mount the net on the goal constructions can cause traumatic finger injuries which happen when a GK with a ring on the finger jumps to put the net over hooks - catch on the ring can lead even to the finger amputation [62]. Contemporary goals have plastic hooks situated parallel to the goal crossbar, which eliminates this type of risk, but older goals should be avoided and replaced.

\subsubsection{Forearms, Arms and Elbows}

GKs often make dives to stop a ball shoot to the corners of the goal, which leads to landing on the ground on the side of the body. These, as well as other, types of interventions and being hit by the ball, contact with the opponent, trampling, contact with a goal construction or accidental falls may evoke a risk of trauma and the forearm, arm and elbow injuries. The results of Muracki et al. shows that $67 \%$ of GKs (16 of 24) indicated pain caused by impact in the area of forearms and shoulders. Joint pain in the elbow region was signaled by $17 \%$ of GKs (4 of 24) and 33\% (8 of 24) indicated muscle pain in the upper limb [61]. Kraus et al., in their report, claim that fractures of the distal radius are the most frequent fractures of long bones during childhood and adolescence, thus the mechanisms of the fracture are differential. The authors analyzed 516 distal radius fractures suffered by children and adolescents, which had different causes. Most of the football radius fractures-48 (78.7\%)-occurred due to falling. The authors focused on football GK injuries and found 13 cases in which the trauma was caused by a sharp shot ball. Patients were reexamined after 10 months and all of them returned to the same sport level [30]. 


\subsubsection{Shoulders}

A number of shoulder injuries is an increasing problem in football, whereas GKs are even more exposed to shoulder disorders than other field players $[23,25]$. Reports from European biggest football tournaments, perceptions and procedures of physicians of football best European representations and studies analyzing electromyographic muscles activity were analyzed to design the upper limbs injury prevention program in football GKs, which was named Fifa11+ Shoulder (Fifa 11+ S) [23].

GKs' actions include different dynamic movements of shoulders, such as throwing a ball, diving and deflecting a ball with one or two hands, catching and punching a ball which can lead to muscle and tendon injuries. Repeated interventions ending in landing on the side of the body on the ground also evoke injury risk in the shoulder area. The research of Strand, Krosshaug and Andersen showed that the most common overuse injuries are located in the shoulder area [35]. The analysis of shoulder and elbow injuries in GKs versus field players in NCAA from season 2009-2010 to 2013-2014 shows that GKs suffer more elbow and shoulder injuries compared to field players-8.3 vs. 1.8 incidents respectively per 10,000 athletic exposures (AE). GKs face even more risk of elbow and shoulder injuries during practice (21.3-fold) and during preseason (16.1-fold) than field players. Female GKs have 7.7-fold higher injury incidents in this location than female field players and 1.9-fold higher than male GKs. The most frequent injuries were acromioclavicular joint injuries, rotator cuff tears/sprains and elbow and shoulder instability [25]. The literature provides evidence that muscles of the shoulder girdle can suffer tear during GKs' dynamic actions, such as ball throwing, punching, or diving. A case study of a football GK with musculotendinous rupture of the distal biceps brachii describes the mechanism of the trauma occurred during an overhead ball throw with a single arm [33]. The case study published by Maciel describes a case of a GK with the teres major tendon rupture [34]. The case study of Fysnetzou presents an injury of latissimus dorsi tear during match play [63]. Though the type of injury is rare, the mechanism is frequent in GKs play and training. Study analyzing GK actions during gameplay in different training games conditions showed that the ball was played with hands by the GK in $58,9 \%$ of offensive actions [10]. GKs' diving causes hazardous falling on the forearm, which can lead to the shoulder dislocation $[23,25,54]$. This type of injury can bring wide complications because of numerous muscles and tendons surrounding the shoulder area, as well as the joint complex structure. Complete return to sport can be extended to a year when complications occur [64].

\subsection{Goalkeeper Injuries of Head, Neck, Chest, Trunk and Back}

There is a gap in scientific literature concerning GK injuries in the area of head (excluding dental trauma), neck, chest, trunk, and back. Injuries of shoulder girdle muscles were presented in the part of this review describing shoulder injuries in this review because they are functionally much more connected with the shoulder, though they are situated in the back.

The literature on head injuries in football concerns mainly heading the ball, which is atypical for GKs. During search process we found one study concerining heading in GK. It reported that GKs made three head hits during the whole season [65] which is far to less to bring any conclusions. The study of Muracki et al. (2019) analyzing pain in GKs showed that only $4 \%$ of GKs ( 1 of 24 ) indicated impact pain in the head and neck area, 38\% (9 of 24 ) reported chest, trunk, and back impact pain. Muscle pain was indicated by $33 \%$ in the chest area (8 of 24$), 29 \%$ ( 7 of 24 ) in the area of the neck and shoulders and $21 \%$ (5 of 24 ) in the area of the abdomen and also $21 \%$ ( 5 of 24 ) in the back. Joint pain was indicated by one GK in the neck area [61]. The study of Tunås et al. (2015) shows that 70\% of female GKs reported low back pain [66]. Female GKs are more prone to suffer concussion comparing to male GKs [67]. 
Football GKs are more endangered to maxillofacial and dental trauma than field players. Some authors recommend that GKs use helmets during the game due to the life-threatening consequences of this type of injury [68-70].

\subsection{Goalkeepers' Injuries of Lower Limbs}

4.6.1. Hips and Groins Regions

The groin and hip area seems to be very often affected by pain and injuries in football GKs, which is the reason why GKs should use protective shorts. In the study of Muracki et al., analyzing pain in GK during a training camp GKs often suffered pain in the lower limbs, groin and hip caused by impact. The area of groin and hip was indicated the most frequently. In terms of muscle pain, GKs frequently reported the thigh, calf and gluteus area and thigh area was the most frequent (88\%, 21 of $24 \mathrm{GKs})$. Joint pain was indicated in the area of groin and hip, knees, and ankles (29\%, 27\%, and 21\%, respectively) [61].

Muscle injuries (rupture, tear, strain, cramps) are the main injury type in the groin and hip area in football players (all positions) and represent $60 \%$ of all injuries in the study of Lundgårdh, Svensson, and Alricsson. Unspecific overuse symptoms, tendon injury, contusion, haematoma, synovitis and other types of injury represent $24 \%, 6 \%, 4 \%$, $1 \%, 1 \%$, and $5 \%$, respectively, of all injuries reported. GKs suffered $6 \%$ of the analyzed hip and groin injuries [71]. In contrast the study of Schmitt et al., which focused on hip and groin injuries, showed that in football GKs of different age, gender and sports level, contusions and abrasions occur the most often. Abrasions were reported by $80-100 \%$ of players and contusions were indicated by $48-71 \%$ depending on a group. Other types of injuries were less frequently reported-synovitis of hip joint by 7-20\%, arthrosis of hip joint only by $3 \%$ and fractures only by $2 \%$ of male amateurs. Bursitis was more often reported by professional than amateur players, but generally amateur players have a higher injury rate than professional ones. The injury risk was higher during training exercises than during a match. It is assumed that the reason is a higher number of interventions and goalkeeper-to-player interactions during training exercises than during the same time amount of match play. The authors state that in their study there was no influence of age, gender and exercise intensity on the injury rate. The injury rate was higher when playing and training on artificial grass compared to natural grass, but the difference was not statistically significant. The use of protective goalkeeper shorts did not influence the injury rate [72].

The further analysis of the issue of protective shorts conducted by Schmitt et al. showed that the best models can reduce impact forces on the hip up to $53 \%$, force acting on the neck of the femur bone by over $63 \%$ and vertical force also by $63 \%$. The authors claim that padded shorts did not influence the observed injury rate but add that it was not measured whether the use of padded shorts changed the injuries severity level [73]. Despite the fact that goalkeeper padded shorts may not provide perfect protection, it may lower the severity of skin abrasions and bruises. Coaches and professionals should consider that repetitive micro trauma caused by overtraining or overuse can cause deformity of the femoral cam and neck in exceptional cases [74].

The anterior inferior iliac spine (AIIS), which is the attachment site of the straight head of the quadriceps muscle of the thigh, is a point with high injury risk. Injuries of proximal rectus femoris avulsion, avulsion fracture, tendon tear and ossification of tendon are presented in the scientific literature [36,37]. Dunsmuir and colleagues described a case study of injury of the anterior superior iliac spine (ASIS) which provides attachment for the inguinal ligament, and the sartorius muscle [22]. A typical injury mechanism occurs when kicking a ball hard during training or match play. Despite the fact the rectus femoris muscle is one of the biggest muscles in the whole human body, the GKs managed to continue play after suffering the injury in the described case study. A proper diagnosis is difficult because the symptoms are unclear and may be present only during kicking or sprinting. That is the reason why GKs may continue not only match play but also the season without thorough examination and treatment and suffer multiple re-injuries. Esser et al. discuss whether 
the surgical operation or conservative treatment is preferable in similar cases, but they recommend early ultrasound or MRI examination to make a proper and differentiating diagnosis [37]. Resnick et al. claim that this type of injuries may be caused by a single forceful contraction or by numerous chronic insults. The trauma may involve ischial tuberosity, anterior inferior iliac spine and anterior superior iliac spine. Adolescents who kick with great force are the most susceptible to these injuries. The authors recommend biopsy to differentiate between avulsion fractures and ossification processes and possible malignancy [36]. Failure to diagnose and treat such injuries complicated by infection could lead to chronic osteomyelitis, bone destruction, or septicaemia [22].

\subsubsection{Knees and Calves}

Knee injuries are common in football. In the study of Błażkiewicz et al., 27\% of GKs reported knee injuries [57]. However, according to Schiffner et al., GKs are significantly less prone to suffer an ACLR injury than outfield players [75]. During a training camp dedicated to GKs $58 \%$ of GKs (14 of 24) indicated pain caused by impact in the knee area and $21 \%$ (5 of 24 ) in calves and feet. Muscle pain was reported in 38\% of participants ( 9 of 24 ) in the calf areas. Joint pain in the knee areas was indicated by $21 \%$ of GKs (5 of 24) [61]. Fractures of tibia and fibula are the most common in youth football players over 13 years of age and are hallmarked by delayed return to sport and complications [76]. Though these fractures are common in football, GKs are less prone to fractures of the lower leg. These fractures typically occur due to contact during slide tackles, a collision of two players, and a standing player's kick. The typical return time is about 40 weeks. The general conclusion is that the lower leg fractures are severe and it is discussed whether shin guards provide satisfactory, if any, protection $[77,78]$.

\subsubsection{Feet and Ankles}

Despite the fact that ankle injuries are common in football [2], the scientific literature lacks articles describing this type of injury in GKs. The results of the study of Muracki et al. showed that $21 \%$ (5 of 24) of GKs felt pain in the area of feet and calves as a result of an impact and 17\% (4 of 24) of GKs indicated pain in the ankle joint [61]. In the study of Błażkiewicz et al., $12 \%$ of GKs reported injury in the foot and ankle areas [57].

Luthje and Nurmi published a case study of a male football GK who suffered an injury of the mid-tarsal region of the foot during a training game. The injury mechanism was excessive abduction-plantar-flexion. The diagnosis was made by means of radiograph, which showed fracture-dislocation of the tarsal navicular. The patient underwent a surgical operation of closed reduction with percutaneous fixation using two Kirschner wires. The pain in the mid-foot prevented the patient from returning to play [79].

\subsection{Summary of the Case Studies}

In most of the cases described in the literaturegoalkeepers were able to go back to sport to the same level of competition (Table 4). The authors underline the importance of a proper and careful diagnosis, implementation of adequate treatment as soon as possible, as well as proper rehabilitation. 
Table 4. Summary of the case studies outlining goalkeeper injuries.

\begin{tabular}{|c|c|c|c|c|c|c|}
\hline Study & $n$ of Cases & Injured Structure & Name of the Injury & Localization & Situation & Average Time Loss \\
\hline Scerri and Ratcliffe (1994) [62] & 3 & Finger & Eing finger avulsion & fingers & Equipment preparation & Unknown/not reported \\
\hline $\begin{array}{c}\text { Charalambous, Rajkumar and } \\
\text { Samarji (2002) [80] }\end{array}$ & 1 & Joints & $\begin{array}{l}\text { Double dislocation of the } \\
\text { proximal and distal } \\
\text { interphalangeal joints of the little } \\
\text { finger }\end{array}$ & fingers & Shot stopping & 3 weeks \\
\hline $\begin{array}{l}\text { Shyamsundar and Macsween } \\
\text { (2005) [81] }\end{array}$ & 1 & Joints & $\begin{array}{l}\text { Simultaneous dislocation of the } \\
\text { proximal and distal } \\
\text { interphalangeal joints of the ring } \\
\text { and middle finger }\end{array}$ & fingers & $1 \mathrm{v} 1$ & 8 weeks \\
\hline $\begin{array}{c}\text { Tomcovcik, Kubasovský and } \\
\text { Kitka (2003) [82] }\end{array}$ & 1 & Joints & $\begin{array}{l}\text { Simultaneous double } \\
\text { interphalangeal dislocation in the } \\
\text { little finger }\end{array}$ & fingers & $1 \mathrm{v} 1$ & 1 week \\
\hline $\begin{array}{l}\text { Degreef and De Smet } \\
\text { (2009) [83] }\end{array}$ & 1 & Tendons & $\begin{array}{l}\text { Multiple simultaneous mallet } \\
\text { fingers }\end{array}$ & fingers & Shot stopping & 7 weeks \\
\hline Giannini et al. (2004) [84] & 1 & Bones & Phalanx fracture & fingers & Not reported & 8 weeks \\
\hline $\begin{array}{l}\text { Perugia, Ciurluini and Ferretti } \\
\text { (2009) [86] }\end{array}$ & 1 & Tendon & $\begin{array}{c}\text { Extensor pollicis longus tendon } \\
\text { rupture }\end{array}$ & hand & Not reported & 16 weeks \\
\hline Green and Rayan (1997) [87] & 2 & Bones & Scaphoid fracture & wrist & Shot stopping & No full treatment \\
\hline Pidemunt et al. (2012) [88] & 1 & Bones & $\begin{array}{l}\text { Bilateral stress fracture of the } \\
\text { carpal scaphoid }\end{array}$ & wrist & Shot stopping & 24 weeks \\
\hline Saglam et al. (2014) [89] & 1 & Bones & Bilateral scaphoid stress fracture & wrist & Not identified & 12 weeks \\
\hline Yammamoto et al. (2019) [31] & 1 & Bones & $\begin{array}{c}\text { Trapezoid Fracture Associated } \\
\text { with Scaphoid Fracture }\end{array}$ & wrist & Cross interception & 20 weeks \\
\hline $\begin{array}{l}\text { Boyd, Brownson and Hunter } \\
\text { (2001) [29] }\end{array}$ & 29 & Bone & Distal radius fracture & forearm & $\begin{array}{l}\text { Shot stopping and } \\
\text { diving save }\end{array}$ & 3.2 weeks \\
\hline Kraus et al. (2007) [30] & 13 & Bone & Distal radius fracture & forearm & Not reported & 3-8 weeks \\
\hline $\begin{array}{c}\text { Lopez-Zabala and } \\
\text { Fernandez-Garcia (2013) [33] }\end{array}$ & 1 & Tendon & $\begin{array}{l}\text { Distal biceps brachii } \\
\text { musculotendinous ruptures }\end{array}$ & arm & Ball throwing & 52 weeks \\
\hline
\end{tabular}


Table 4. Cont.

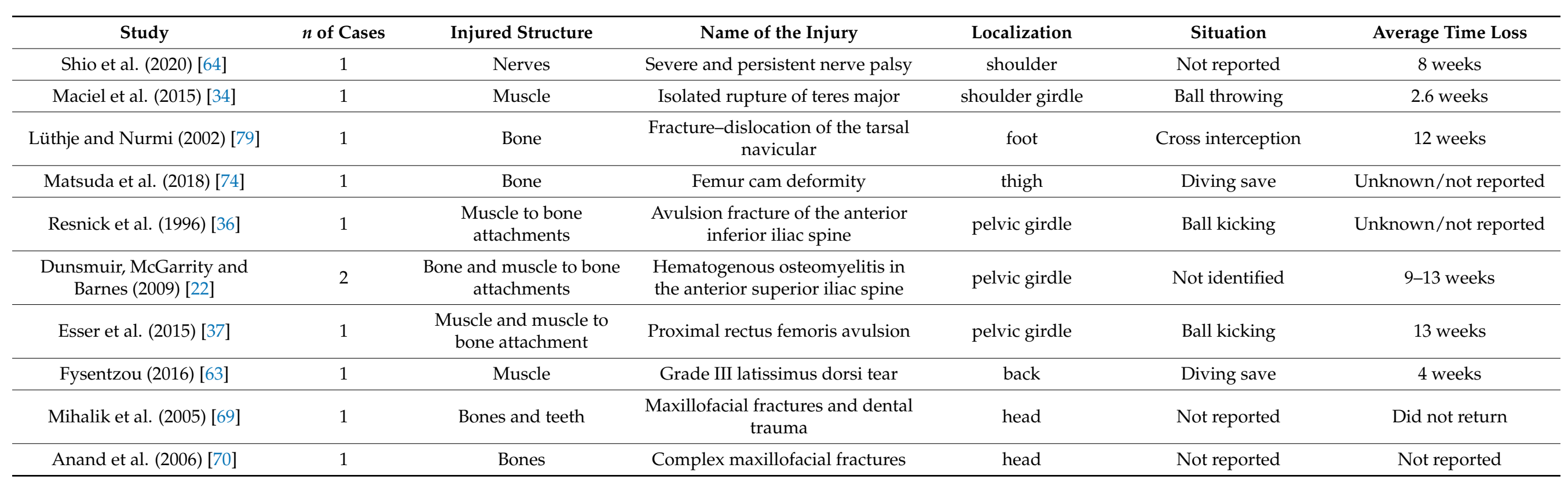




\subsection{Injury Prevention Strategies}

Injuries can lead to the cessation of participation in football activities including goalkeeping training, can slow down career development, as well as cause delayed effects after the end of football career. The injury hazard ratio increases with age, which makes it even more necessary to design preventing programs. The programs should be dedicated to GKs, implemented in training routines and evaluated. Studies on delayed effects of football goalkeeper training and playing should be conducted to describe the possible consequences.

The FIFA 11+ injury prevention program includes three stages with 15 different warmup exercises performed in the exact order and a specific number of repetitions performed at least twice per week. A systematic review prepared by Sadigursky et al. (2017) revealed that the FIFA $11+$ reduced the injury by $30 \%$ [90].

About one-third of shoulder injuries are severe and cause time loss over 28 days [23] which strongly justifies the implementation of a preventive program. The Fifa 11+ shoulder injury prevention program for GKs was designed on the basis of theanalysis of increasing incidence of upper limb and shoulder injuries [23]. Its effects, however, still need evaluation and assesment.

The injury prevention strategies should aim to decrease overuse and acute injuries rate, lower their burden and, in longer perspective, let preserve better health. It seems even more important for GKs who are reported to live 5-8 years longer than football players in other football positions [91].

\section{Conclusions}

A synthesis of the available literature suggests that football GKs have different injury patterns (type, localization, severity, mechanism, burden) due to their specific characteristics and conditions during game and training compared with outfield players. There are still some controversies whether GKs have the same or lower injury incidence compared to other positions. Still more scientific evidence is needed to prove whether GKs suffer more injuries in training than in matches, but it seems rational due to more goalkeeper-to-player interactions and more goalkeeping actions during training sessions comparing to matches.

The most frequent injuries of football GKs reported in the literature are fractures, luxations and dislocations in fingers, hands, and wrists, as well as muscle and tendon damage in the upper and lower limbs-especially the quadriceps femoris, and forearms muscles and tendons moving hands and fingers. There are also differences in incidence, risk and mechanisms of injuries due to overload-specific risk factors for GKs. The highest injury risk has been evaluated mainly for the upper limbs (shoulder, hand, wrist and fingers), because the most overloading and injury occur during diving saves, ball catches, and direct contact with other players. However, further precise research is needed for an absolute explanation.

\subsection{Practical Applications and Recommendation}

This narrative review provides some practical applications, which might be used by GK coaches, strength and conditioning coaches, athletic therapists, physical therapist, as well as by GKs themselves. First, the right ball size should be used during training in different age groups, i.e., up to 8 years old (size 3), from 9 to 12 years old (size 4 ) and from 13 years old and older (size 5). Therapeutic care should consider pain symptoms in the shoulder, wrist, hip, and groin and thigh early, because of high risk of overloading and injury during diving saves, catching and kicking the ball. Furthermore, pain symptoms should not be downplayed as part of the game and should be monitored instead. Such monitoring will allow players, coachers and therapists to understand the true duration and characteristics of pain symptoms. 


\subsection{Future Research Directions}

Due to the identified knowledge gaps-injuries and pain in female GKs, young GKs, preventive program designs and their effectiveness, as well as particular injury locations considered to be crucial in field players - knee, groin, and shoulder injuries further research directions are suggested. There is also the lack of research on GK injuries of the head, neck and chest which can be very traumatic. Further research should be directed at the examination of gender and age-related differences in pain and injury mechanisms, based on the injury type and localization in football GKs. To obtain this effect, digital pain mapping can be used to replenish and enrich data assessing injury incidence. Preventive programs should be designed and their effectiveness assessed. Future research should coherently use definitions according to injury definitions described in the Consensus statement [38] to bring findings which would develop knowledge about football GK injuries and improve the prevention programs whose efficiency should be also scientifically evaluated. According to Bahr et al., analysis, not only of injury incidence, but also injury burden [92], is recommended.

Author Contributions: Ideation: J.M.; literature search and data analysis: J.M.; draft preparation: J.M. and S.A.B.; revision: A.K., S.K., S.A.B. and J.M. All authors have read and agreed to the published version of the manuscript.

Funding: This research received no external funding.

Institutional Review Board Statement: Not applicable.

Informed Consent Statement: Not applicable.

Data Availability Statement: No new data were created or analyzed in this study. Data sharing is not applicable to this article.

Conflicts of Interest: The authors declare no conflict of interest.

\section{References}

1. DeHaven, K.E.; Lintner, D.M. Athletic injuries: Comparison by age, sport, and gender. Am. J. Sports Med. 1986, 14, 218-224. [CrossRef] [PubMed]

2. Hootman, J.M.; Dick, R.; Agel, J. Epidemiology of collegiate injuries for 15 sports: Summary and recommendations for injury prevention initiatives. J. Athl. Train. 2007, 42, 311-319. Available online: www.journalofathletictraining.org (accessed on 22 February 2021). [PubMed]

3. Gil, S.M.; Zabala-Lili, J.; Bidaurrazaga-Letona, I.; Aduna, B.; Lekue, J.A.; Santos-Concejero, J.; Granados, C. Talent identification and selection process of outfield players and goalkeepers in a professional soccer club. J. Sports Sci. 2014, 32, 1931-1939. [CrossRef] [PubMed]

4. Leão, C.; Camões, M.; Clemente, F.M.; Nikolaidis, P.T.; Lima, R.; Bezerra, P.; Rosemann, T.; Knechtle, B. Anthropometric Profile of Soccer Players as a Determinant of Position Specificity and Methodological Issues of Body Composition Estimation. Int. J. Environ. Res. Public Health 2019, 16, 2386. [CrossRef] [PubMed]

5. De Baranda, P.S.; Ortega, E.; Palao, J.M. Analysis of goalkeepers' defence in the World Cup in Korea and Japan in 2002. Eur. J. Sport Sci. 2008, 8, 127-134. [CrossRef]

6. Di Salvo, V.; Benito, P.J.; Calderón, F.J.; Di Salvo, M.; Pigozzi, F. Activity profile of elite goalkeepers during football match-play. J. Sports Med. Phys. Fit. 2008, 48, 443-446.

7. Ziv, G.; Lidor, R. Physical Characteristics, Physiological Attributes, and On-Field Performances of Soccer Goalkeepers. Int. J. Sports Physiol. Perform. 2011, 6, 509-524. [CrossRef]

8. Liu, H.; Gómez, M.A.; Lago-Peñas, C. Match Performance Profiles of Goalkeepers of Elite Football Teams. Int. J. Sports Sci. Coach. 2015, 10, 669-682. [CrossRef]

9. Otte, F.W.; Millar, S.-K.; Klatt, S.; Hüttermann, S. How does the modern football goalkeeper train?-An exploration of expert goalkeeper coaches' skill training approaches. J. Sports Sci. 2019, 38, 1465-1473. [CrossRef]

10. Jara, D.; Ortega, E.; Gomez, M.-A.; De Baranda, P.S. Effect of Pitch Size on Technical-Tactical Actions of the Goalkeeper in Small-Sided Games. J. Hum. Kinet. 2018, 62, 157-166. [CrossRef]

11. White, A.; Hills, S.P.; Cooke, C.B.; Batten, T.; Kilduff, L.P.; Cook, C.J.; Roberts, C.; Russell, M. Match-Play and Performance Test Responses of Soccer Goalkeepers: A Review of Current Literature. Sports Med. 2018, 48, 2497-2516. [CrossRef]

12. White, A.; Hills, S.P.; Hobbs, M.; Cooke, C.B.; Kilduff, L.P.; Cook, C.; Roberts, C.; Russell, M. The physical demands of professional soccer goalkeepers throughout a week-long competitive microcycle and transiently throughout match-play. J. Sports Sci. 2020, 38, 848-854. [CrossRef] 
13. Stølen, T.; Chamari, K.; Castagna, C.; Wisløff, U. Physiology of Soccer. Sports Med. 2005, 35, 501-536. [CrossRef]

14. Bangsbo, J.; Mohr, M.; Krustrup, P. Physical and metabolic demands of training and match-play in the elite football player. J. Sports Sci. 2006, 24, 665-674. [CrossRef]

15. Krustrup, P.; Mohr, M.; Steensberg, A.; Bencke, J.; Kjær, M.; Bangsbo, J. Muscle and Blood Metabolites during a Soccer Game. Med. Sci. Sports Exerc. 2006, 38, 1165-1174. [CrossRef]

16. Di Salvo, V.; Baron, R.; Tschan, H.; Montero, F.J.C.; Bachl, N.; Pigozzi, F. Performance Characteristics According to Playing Position in Elite Soccer. Int. J. Sports Med. 2007, 28, 222-227. [CrossRef]

17. Di Salvo, V.; Gregson, W.; Atkinson, G.; Tordoff, P.; Drust, B. Analysis of High Intensity Activity in Premier League Soccer. Int. J. Sports Med. 2009, 30, 205-212. [CrossRef]

18. Russell, M.; Rees, G.; Benton, D.; Kingsley, M. An Exercise Protocol that Replicates Soccer Match-Play. Int. J. Sports Med. 2011, 32, 511-518. [CrossRef]

19. Barnes, C.; Archer, D.T.; Hogg, B.; Bush, M.; Bradley, P.S. The Evolution of Physical and Technical Performance Parameters in the English Premier League. Int. J. Sports Med. 2014, 35, 1095-1100. [CrossRef]

20. Russell, M.; Sparkes, W.; Northeast, J.; Cook, C.J.; Love, T.D.; Bracken, R.M.; Kilduff, L.P. Changes in Acceleration and Deceleration Capacity Throughout Professional Soccer Match-Play. J. Strength Cond. Res. 2016, 30, 2839-2844. [CrossRef]

21. Mohr, M.; Krustrup, P.; Bangsbo, J. Match performance of high-standard soccer players with special reference to development of fatigue. J. Sports Sci. 2003, 21, 519-528. [CrossRef] [PubMed]

22. Dunsmuir, R.A.; McGarrity, G.; Barnes, S. “Goalkeeper's hip": Acute haematogenous osteomyelitis secondary to apophyseal fractures. BMJ Case Rep. 2009, 2009. [CrossRef] [PubMed]

23. Ejnisman, B.; Andreoli, C.V.; Pochini, A.D.C.; Cohen, M.; Bizzini, M.; Dvorak, J.; Zogaib, R.; Lobo, T.; Barbosa, G. Shoulder injuries in soccer goalkeepers: Review and development of a FIFA $11+$ shoulder injury prevention program. Open Access J. Sports Med. 2016, 7, 75-80. [CrossRef]

24. Della Villa, F.; Mandelbaum, B.R.; Lemak, L.J. The Effect of Playing Position on Injury Risk in Male Soccer Players: Systematic Review of the Literature and Risk Considerations for Each Playing Position. Am. J. Orthop. 2018, 47. [CrossRef] [PubMed]

25. Goodman, A.D.; Etzel, C.; Raducha, J.E.; Owens, B.D. Shoulder and elbow injuries in soccer goalkeepers versus field players in the National Collegiate Athletic Association, 2009-2010 through 2013-2014. Physician Sportsmed. 2018, 46, 1-8. [CrossRef] [PubMed]

26. Ibrahim, R.; Kingma, I.; De Boode, V.; Faber, G.S.; Van Dieën, J.H. The Effect of Preparatory Posture on Goalkeeper's Diving Save Performance in Football. Front. Sports Act. Living 2019, 1, 15. [CrossRef] [PubMed]

27. Ibrahim, R.; Kingma, I.; De Boode, V.A.; Faber, G.S.; Van Dieën, J.H. Kinematic and kinetic analysis of the goalkeeper's diving save in football. J. Sports Sci. 2019, 37, 313-321. [CrossRef]

28. Ibrahim, R.; Kingma, I.; De Boode, V.; Faber, G.S.; Van Dieën, J.H. Angular Velocity, Moment, and Power Analysis of the Ankle, Knee, and Hip Joints in the Goalkeeper's Diving Save in Football. Front. Sports Act. Living 2020, 2, 13. [CrossRef]

29. Boyd, K.T. Distal radial fractures in young goalkeepers: A case for an appropriately sized soccer ball. Br. J. Sports Med. 2001, 35, 409-411. [CrossRef]

30. Kraus, R.; Szalay, G.; Meyer, C.; Kilian, O.; Schnettler, R. Die Distale Radiusfraktureine Torwartverletzung bei Kindern und Jugendlichen. Sportverletz. Sportschaden 2007, 21, 177-179. [CrossRef]

31. Yamamoto, T.; Matsushita, T.; Ito, K.; Matsushima, S.; Yoshida, K.; Kuroda, R. Trapezoid Fracture Associated with Scaphoid Fracture in a Football Goalkeeper. Case Rep. Orthop. 2019, 2019, 1-4. [CrossRef] [PubMed]

32. Hilber, F.; Wiesenberg, A.; Kerschbaum, M.; Ernstberger, A.; Worlicek, M.; Nerlich, M.; Prantl, L.; Koch, M.; Krutsch, V.; Krutsch, W. Functional Deficits in the Wrist and Finger Joints of Goalkeepers After 20 Years of Playing Recreational Football. Sportverletz. Sportschaden 2019, 33, 142-148. [CrossRef] [PubMed]

33. López-Zabala, I.; Fernández-Valencia, J.A. Nonoperative Treatment of Distal Biceps Brachii Musculotendinous Partial Rupture: A Report of Two Cases. Case Rep. Orthop. 2013, 2013, 1-3. [CrossRef] [PubMed]

34. Maciel, R.A.; Zogaib, R.K.; Pochini, A.D.C.; Ejnisman, B. Isolated rupture of teres major in a goalkeeper. BMJ Case Rep. 2015, 2015, 1-5. [CrossRef]

35. Strand, E.; Krosshaug, T.; Andersen, T.E. Injury risk for goalkeepers in norwegian male professional football. Br. J. Sports Med. 2011, 45, 331. [CrossRef]

36. Resnick, J.M.; Carrasco, C.H.; Edeiken, J.; Yasko, A.W.; Ro, J.Y.; Ayala, A.G. Avulsion fracture of the anterior inferior iliac spine with abundant reactive ossification in the soft tissue. Skelet. Radiol. 1996, 25, 580-584. [CrossRef]

37. Esser, S.; Jantz, D.; Hurdle, M.F.; Taylor, W. Proximal Rectus Femoris Avulsion: Ultrasonic Diagnosis and Nonoperative Management. J. Athl. Train. 2015, 50, 778-780. [CrossRef]

38. Fuller, C.W.; Ekstrand, J.; Junge, A.; E Andersen, T.; Bahr, R.; Dvorak, J.; Hägglund, M.; McCrory, P.; Meeuwisse, W.H. Consensus statement on injury definitions and data collection procedures in studies of football (soccer) injuries. Br. J. Sports Med. 2006, 40, 193-201. [CrossRef]

39. Bahr, R. No injuries, but plenty of pain? On the methodology for recording overuse symptoms in sports. Br. J. Sports Med. 2009, 43, 966-972. [CrossRef] 
40. Raja, S.N.; Carr, D.B.; Cohen, M.; Finnerup, N.B.; Flor, H.; Gibson, S.; Keefe, F.J.; Mogil, J.S.; Ringkamp, M.; Sluka, K.A.; et al. The revised International Association for the Study of Pain definition of pain: Concepts, challenges, and compromises. Pain 2020, 161, 1976-1982. [CrossRef]

41. Kumar, K.H.; Elavarasi, P. Definition of pain and classification of pain disorders. J. Adv. Clin. Res. Insights 2016, 3, 87-90. [CrossRef]

42. Kirkendall, D.T.; Dvorak, J. Effective Injury Prevention in Soccer. Physician Sportsmed. 2010, 38, 147-157. [CrossRef]

43. Andersen, T.E.; Larsen, Ø; Tenga, A.; Engebretsen, L.; Bahr, R. Football incident analysis: A new video based method to describe injury mechanisms in professional football. Br. J. Sports Med. 2003, 37, 226-232. [CrossRef]

44. Aoki, H.; O’Hata, N.; Kohno, T.; Morikawa, T.; Seki, J. A 15-Year Prospective Epidemiological Account of Acute Traumatic Injuries During Official Professional Soccer League Matches in Japan. Am. J. Sports Med. 2012, 40, 1006-1014. [CrossRef]

45. Arliani, G.G.; Belangero, P.S.; Runco, J.L.; Cohen, M. The Brazilian Football Association (CBF) model for epidemiological studies on professional soccer player injuries. Clinics 2011, 66, 1707-1712. [CrossRef]

46. Kristenson, K.; Waldén, M.; Ekstrand, J.; Hägglund, M. Lower Injury Rates for Newcomers to Professional Soccer. Am. J. Sports Med. 2013, 41, 1419-1425. [CrossRef]

47. Deehan, D.J.; Bell, K.; McCaskie, A.W. Adolescent musculoskeletal injuries in a football academy. J. Bone Jt. Surgery. Br. Vol. 2007, 89, 5-8. [CrossRef]

48. Carling, C.; Orhant, E.; Le Gall, F. Match Injuries in Professional Soccer: Inter-Seasonal Variation and Effects of Competition Type, Match Congestion and Positional Role. Int. J. Sports Med. 2009, 31, 271-276. [CrossRef]

49. Agustín, R.M.-S.; Medina-Mirapeix, F.; Esteban-Catalán, A.; Escriche-Escuder, A.; Sánchez-Barbadora, M.; Benítez-Martínez, J. Epidemiology of Injuries in First Division Spanish Women's Soccer Players. Int. J. Environ. Res. Public Health 2021, 18, 3009. [CrossRef]

50. Dauty, M.; Collon, S. Incidence of Injuries in French Professional Soccer Players. Int. J. Sports Med. 2011, 32, 965-969. [CrossRef]

51. Morgan, B.E.; Oberlander, M.A. An Examination of Injuries in Major League Soccer. Am. J. Sports Med. 2001, 29, 426-430. [CrossRef]

52. Timpka, T.; Risto, O.; Björmsjö, M. Boys soccer league injuries: A community-based study of time-loss from sports participation and long-term sequelae. Eur. J. Public Health 2007, 18, 19-24. [CrossRef]

53. Andersson, J.K.; Bengtsson, H.; Waldén, M.; Karlsson, J.; Ekstrand, J. Hand, Wrist, and Forearm Injuries in Male Professional Soccer Players: A Prospective Cohort Study of 558 Team-Seasons From 2001-2002 to 2018-2019. Orthop. J. Sports Med. 2021, 9 , 2325967120977091. [CrossRef]

54. Hart, D.; Funk, L. Serious shoulder injuries in professional soccer: Return to participation after surgery. Knee Surg. Sports Traumatol. Arthrosc. 2013, 23, 2123-2129. [CrossRef]

55. Ekstrand, J.; Hägglund, M.; Törnqvist, H.; Kristenson, K.; Bengtsson, H.; Magnusson, H.; Waldén, M. Upper extremity injuries in male elite football players. Knee Surg. Sports Traumatol. Arthrosc. 2013, 21, 1626-1632. [CrossRef]

56. Hwang-Bo, K.; Joo, C.-H. Analysis of injury incidences in the Korea national men's soccer teams. J. Exerc. Rehabil. 2019, 15, 861-866. [CrossRef]

57. Błażkiewicz, A.; Grygorowicz, M.; Białostocki, A.; Czaprowski, D. Characteristics of goalkeeping injuries: A retrospective, self-reported study in adolescent soccer players. J. Sports Med. Phys. Fit. 2018, 58, 1823-1830. [CrossRef]

58. Thorborg, K.; Serner, A.; Petersen, J.; Madsen, T.M.; Magnusson, P.; Hölmich, P. Hip Adduction and Abduction Strength Profiles in Elite Soccer Players. Am. J. Sports Med. 2010, 39, 121-126. [CrossRef]

59. Thorborg, K.; Branci, S.; Stensbirk, F.; Jensen, J.; Hölmich, P. Copenhagen hip and groin outcome score (HAGOS) in male soccer: Reference values for hip and groin injury-free players. Br. J. Sports Med. 2014, 48, 557-559. [CrossRef]

60. Hölmich, P.; Thorborg, K.; Dehlendorff, C.; Krogsgaard, K.; Gluud, C. Incidence and clinical presentation of groin injuries in sub-elite male soccer. Br. J. Sports Med. 2013, 48, 1245-1250. [CrossRef]

61. Muracki, J.; Kumorek, M.; Kisilewicz, A.; Pożarowszczyk, B.; Larsen, D.B.; Kawczyński, A.; Boudreau, S. Practical Use of the Navigate Pain Application for the Assessment of the Area, Location, and Frequency of the Pain Location in Young Soccer Goalkeepers. J. Hum. Kinet. 2019, 69, 125-135. [CrossRef] [PubMed]

62. Scerri, G.V.; Ratcliffe, R.J. The Goalkeeper's Fear of the Nets. J. Hand Surg. 1994, 19, 459-460. [CrossRef]

63. Fysentzou, C. Rehabilitation after a grade III latissimus dorsi tear of a soccer player: A case report. J. Back Musculoskelet. Rehabil. 2016, 29, 905-916. [CrossRef] [PubMed]

64. Shio, H.; Sakura, S.; Motooka, A.; Sakai, Y.; Saito, Y. Severe and persistent nerve palsy after ultrasound-guided continuous interscalene brachial plexus block in a teenager undergoing shoulder surgery: A case report. JA Clin. Rep. 2020, 6, 1-5. [CrossRef]

65. Lamond, L.C.; Caccese, J.B.; Buckley, T.A.; Glutting, J.; Kaminski, T.W. Linear Acceleration in Direct Head Contact Across Impact Type, Player Position, and Playing Scenario in Collegiate Women's Soccer Players. J. Athl. Train. 2018, 53, 115-121. [CrossRef]

66. Tunås, P.; Nilstad, A.; Myklebust, G. Low back pain in female elite football and handball players compared with an active control group. Knee Surg. Sports Traumatol. Arthrosc. 2014, 23, 2540-2547. [CrossRef]

67. Dave, U.; Kinderknecht, J.; Cheng, J.; Santiago, K.; Jivanelli, B.; Ling, D.I. Systematic review and meta-analysis of sex-based differences for concussion incidence in soccer. Physician Sportsmed. 2021, 1-9. [CrossRef]

68. Nysether, S. Dental injuries among Norwegian soccer players. Community Dent. Oral Epidemiol. 1987, 15, 141-143. [CrossRef] 
69. Mihalik, J.P.; Myers, J.B.; Sell, T.C.; Anish, E.J. Maxillofacial Fractures and Dental Trauma in a High School Soccer Goalkeeper: A Case Report. J. Athl. Train. 2005, 40, 116-119.

70. Anand, R.; Ethunandan, M.; Ramchandani, P.; Brennan, P. Perils of football goalkeepers. Br. J. Oral Maxillofac. Surg. 2007, 45, 603-604. [CrossRef]

71. Lundgårdh, F.; Svensson, K.; Alricsson, M. Epidemiology of hip and groin injuries in Swedish male first football league. Knee Surg. Sports Traumatol. Arthrosc. 2019, 28, 1325-1332. [CrossRef]

72. Schmitt, K.U.; Nusser, M.; Boesiger, P. Hip injuries in professional and amateur soccer goalkeepers. Sportverletz. Sportschaden 2008, 22, 159-163. [CrossRef]

73. Schmitt, K.U.; Nusser, M.; Derler, S.; Boesiger, P. Analysing the protective potential of padded soccer goalkeeper shorts. Br. J. Sports Med. 2008, 44, 426-429. [CrossRef]

74. Matsuda, Y.; Kobayashi, N.; Inaba, Y.; Kubota, S.; Yukizawa, Y.; Choe, H.; Kato, I.; Ohashi, K.; Saito, T. Reactive Osteochondromatous Lesion of the Femoral Neck in a Highly Active Preadolescent Patient: Is This the Pathogenesis of a Cam Deformity? Clin. J. Sport Med. 2018, 28, e92-e94. [CrossRef]

75. Schiffner, E.; Latz, D.; Grassmann, J.P.; Schek, A.; Thelen, S.; Windolf, J.; Schneppendahl, J.; Jungbluth, P. Anterior cruciate ligament ruptures in German elite soccer players: Epidemiology, mechanisms, and return to play. Knee 2018, 25, 219-225. [CrossRef]

76. Zaki, P.; Khakimov, S.; Hess, J.; Hennrikus, W. Femur, Tibia, and Fibula Fractures Secondary to Youth Soccer: A Descriptive Study and Review of the Literature. Cureus 2020, 12, 8185. [CrossRef]

77. Boden, B.P. Leg Injuries and Shin Guards. Clin. Sports Med. 1998, 17, 769-777. [CrossRef]

78. Boden, B.P.; Lohnes, J.H.; Nunley, J.A.; Garet, W.E., Jr. Tibia and fibula fractures in soccer players. Knee Surg. Sports Traumatol. Arthrosc. 1999, 7, 262-266. [CrossRef] [PubMed]

79. Lüthje, P.; Nurmi, I. Fracture-dislocation of the tarsal navicular in a soccer player. Scand. J. Med. Sci. Sports 2002, 12, 236-240. [CrossRef]

80. Samarji, R.; Charalambous, C.P.; Rajkumar, P. Double dislocation of the proximal and distal interphalangeal joints of the little finger. Int. J. Clin. Pr. 2002, 56, 816.

81. Shyamsundar, S.; Macsween, W. Simultaneous dorsal dislocation of the interphalangeal joints in ring finger with proximal interphalangeal joint dislocation of the middle finger: Case report and review of the literature. Hand Surg. 2005, 10, 271-274. [CrossRef] [PubMed]

82. Tomcovcík, L.; Kubasovský, J.; Kitka, M. Simultaneous double interphalangeal dislocation on a single finger. Acta Chir. Orthop. Traumatol. Cechoslov. 2003, 70, 309-310.

83. Degreef, I.; De Smet, L. Multiple simultaneous mallet fingers in goalkeeper. Hand Surg. 2009, 14, 143-144. [CrossRef]

84. Giannini, S.; Giombini, A.; Moneta, M.R.; Massazza, G.; Pigozzi, F. Low-Intensity Pulsed Ultrasound in the Treatment of Traumatic Hand Fracture in an Elite Athlete. Am. J. Phys. Med. Rehabil. 2004, 83, 921-925. [CrossRef]

85. Mills, S.P.; Charalambous, C.P.; Hayton, M.J. Bilateral rupture of the extensor pollicis longus tendon in a professional goalkeeper following steroid injections for extensor tenosynovitIS. Hand Surg. 2009, 14, 135-137. [CrossRef]

86. Perugia, D.; Ciurluini, M.; Ferretti, A. Spontaneous rupture of the extensor pollicis longus tendon in a young goalkeeper: A case report. Scand. J. Med. Sci. Sports 2008, 19, 257-259. [CrossRef]

87. Green, J.R.; Rayan, G.M. Scaphoid fractures in soccer goalkeepers. J. Okla. State Med Assoc. 1997, 90, $45-47$.

88. Pidemunt, G.; Torres-Claramunt, R.; Ginés, A.; De Zabala, S.; Cebamanos, J. Bilateral Stress Fracture of the Carpal Scaphoid. Clin. J. Sport Med. 2012, 22, 511-513. [CrossRef]

89. Saglam, F.; Gulabi, D.; Baysal, Ö.; Bekler, H.I.; Taşdemir, Z.; Elmali, N. Chronic wrist pain in a goalkeeper; bilateral scaphoid stress fracture: A case report. Int. J. Surg. Case Rep. 2015, 7, 20-22. [CrossRef]

90. Sadigursky, D.; Braid, J.A.; De Lira, D.N.L.; Machado, B.A.B.; Carneiro, R.J.F.; Colavolpe, P.O. The FIFA 11+ injury prevention program for soccer players: A systematic review. BMC Sports Sci. Med. Rehabil. 2017, 9, 1-8. [CrossRef]

91. Śmigielski, W.; Gajda, R.; Małek, Ł.; Drygas, W. Goalkeepers Live Longer than Field Players: A Retrospective Cohort Analysis Based on World-Class Football Players. Int. J. Environ. Res. Public Health 2020, 17, 6297. [CrossRef]

92. Bahr, R.; Clarsen, B.; Ekstrand, J. Why we should focus on the burden of injuries and illnesses, not just their incidence. Br. J. Sports Med. 2018, 52, 1018-1021. [CrossRef] [PubMed] 